\title{
Precollagen Type III N-terminal Propeptide (PIIINP) a Biomarker Onset in Hypertensive Patients
}

\author{
Hasanain Fadhil Mohammed ${ }^{1 *}$, Sarah Hassan Jaber $^{2 *}$, Ali Jabbar al-Zubaidi ${ }^{3}$ \\ 1,2,3 Medical Laboratory Techniques, Al-Toosi University College, Iraq \\ *e-mail: hassanein@altoosi.edu.iq, sarah.h.jaber@altoosi.edu.iq
}

\begin{abstract}
The aim of this study is to asses PIIINP, lipid profile and BMI serum levels in patients with hypertension. The current research The results were Get it from the Draw Blood unity in Al-Sadder infirmary Teaching, Al-Najaf, Iraq, And AL HAKEEM General infirmary in AL-Najaf, Iraq, in 10 Dec 2018 - 19 Jan 2019. Age of hypertensive patients from 40 to Age 70 Normal blood pressure 40 to 70 years. The score show, serious increase $(p<0.05)$ in PIIINP compared with control groups in patients with hypertension. For female patients, the findings of the reported substantially increased $(p<0.05)$ for PIIINP relative to male patient groups. The findings showed a substantial increase $(p<0.05)$ in PIIINP in age (60-70) relative to age (50-59) and (40-49) and increased substantially $(p<0.05)$ in PIIINP in age (50-59) relative to age (40-49); The results showed significant differences in BMI between the hypertensive and the normotensive.
\end{abstract}

Keywords: Hypertension, Biomarkers, PIIINP, BMI

\author{
Article Information \\ Received: November 20, 2020; Online: December 4, 2020
}

\section{INTRODUCTION}

Hypertension (HT), else named pulse is high (HBP), is a since quite a while ago dated clinical case This has raised the circulatory strain steadily In the Artery (Naish and Jeannette, 2014). Hypertension doesn't as a rule cause symptoms.("High Blood Pressure Fact Sheet"2015) Nevertheless, hypertension is a significant factor hazard for coronary course illness, stroke, breakdown cardiovascular, fibrillation atrial, fringe, vascular infection, vision, misfortune, incessant, kidney a ailment, and a dementia ( Lackland a and Weber., 2015). (Hernandorena et al., 2017 ) ( Lau et al., 2017).

A remaining 5-10 percent of cases are identified as a secondary great blood a pressure, described as pressure higher due to recognizable causes, such as disease of kidney chronic, arteries of kidney narrow, syndrome endocrine or a use of birth, control pills (Poulter, 2015).

A systolic and a diastolic pressures are e two measurements of pressure, which are a, maximum and minimum pressures, respectively. ("High Blood Pressure Fact
Sheet"2015 ). Normal pressure in adult is within $100-130 \mathrm{mmHg}$ systolic and $60-80 \mathrm{mmHg}$ ,diastolic. If pressure is higher than $130 / 80$ or $140 / 90 \mathrm{mmHg}$ is consider higher (Giuseppe et al., 2013 ) (Paul et al., 2017 ) .

During this process, the N-terminal propeptide (PIIINP; MW 45000) is produced in equimolar proportions to collagen type III and enters circulation. Accordingly, serum levels of PIIINP can be used as a collagen synthesis measurement (Cisbio, 2017).

\section{METHODS}

Eighty patients's sample were divided into two study groups normal and Abnormal: This groups Studied as male and female and have subgroup age Categories to [ $40-49$ years ], [ $50-59$ years ] and [ $60-70$ years ]

The Abnormal male groupe have: [ $40-49$ years ]$=[50-59$ years $]=$ and $[60-70$ years $]=$ The Abnormal female groupe have : [ $40-49$ years ]$=[50-59$ years $]=$ and $[60-70$ years $]=$ 
The Normal male groupe have : [ $40-49$ years ]$=[50-59$ years $]=$ and $[60-70$ years $]=$

The Normal female groupe have : [ 40 - 49 years ]$=[50-59$ years $]=$ and $[60-70$ years $]=$

The specimen was compile from the Draw Blood unity in Al-Sadder infirmary Teaching, Al-Najaf, Iraq, And AL HAKEEM General infirmary in AL-Najaf, Iraq, in 10 Dec 2018 19 Jan 2019. The time of Hypertention Patient from 40 to 70 years and time of Normal pulse 40 to 70 years. All members were liable to agerelated surveys, clinical history, family ancestry of circulatory strain, interminable diseases, smoking, blood tests were gathered and submitted for audit. The examination is advised to the two patients and the experimental group, and assent has been guaranteed.

\section{RESULTS}

Biomarkers

\section{Comparison of PIIINP in hypertension} patients compared with control gatherings.

The outcome of figure (1) uncovered fundamentally expanded $(\mathrm{p}<0.05)$ in PIIINP in hypertension patients contrasted and control gatherings.

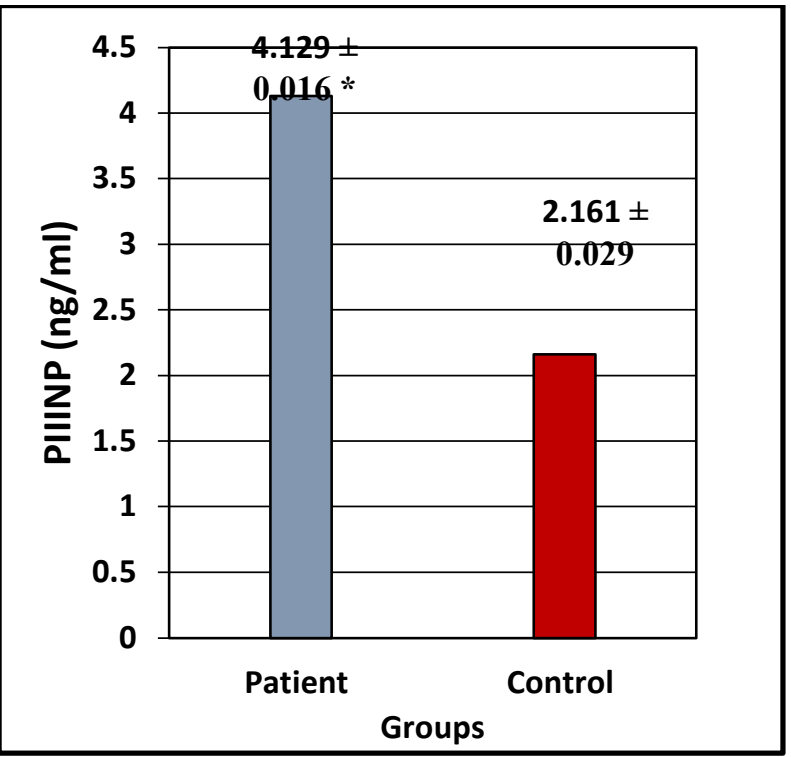

$(*)$ :Measurably huge contrasts $(\mathrm{p}<0.05)$, among PIIINP and control

Figure (1): Comparison of PIIINP in hypertension patients compared with control groups.
Comparison of PIIINP in hypertension patients between female and male. the outcome of figure ( 2 ) uncovered essentially expanded $(p<0.05)$ in PIIINP in female patients contrasted and male patients gatherings.

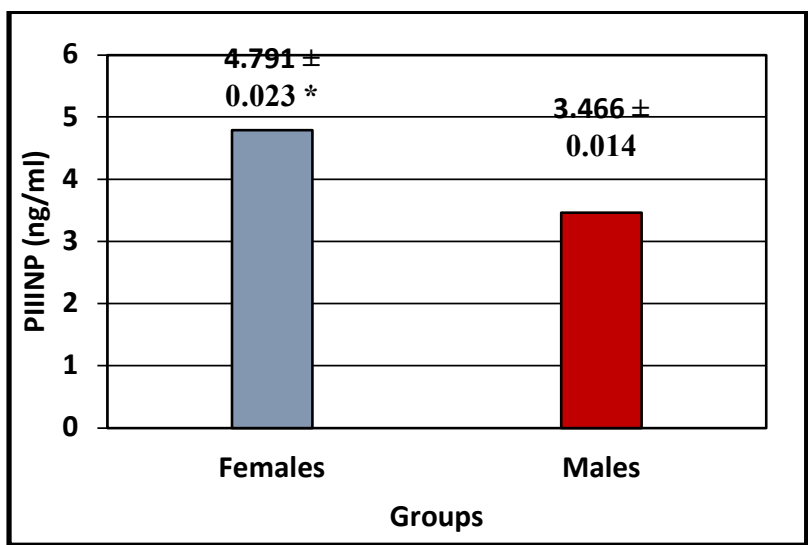

Significant differences $\left({ }^{*}\right)$ :Statistically $(p<0.05)$, between women and man patients

Figure (2): Comparison of PIIINP in hypertension patients between male and female.

\section{Comparison of PIIINP in hypertension patients among different age groups}

The results of figure (3) revealed significantly increased $(\mathrm{p}<0.05)$ in PIIINP in age (60-70) compared with age (50-59) and (40$49)$ and significantly increased $(p<0.05)$ in PIIINP in age (50-59) compared with age(4049)

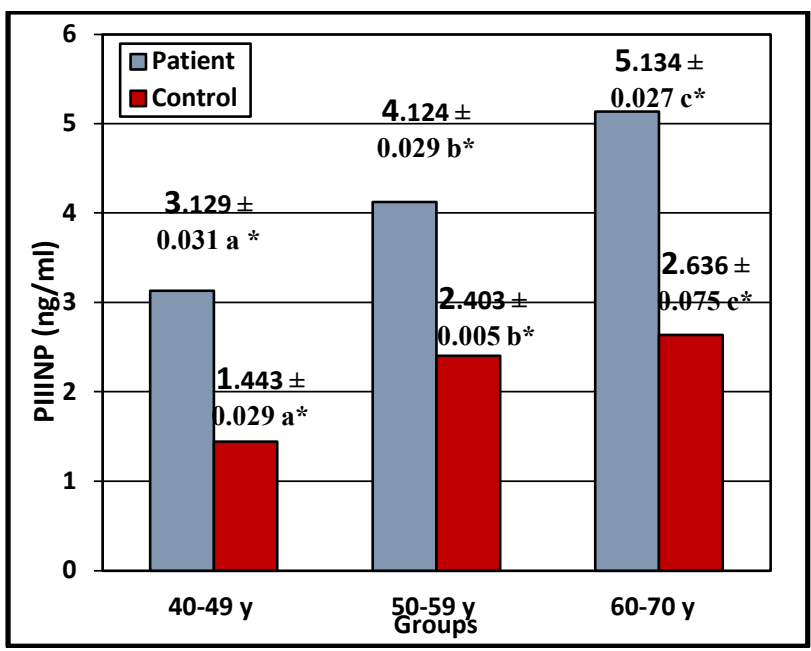

$(*)$ :Measurably huge contrasts $(\mathrm{p}<0.05)$, among various age gatherings.

Figure (3): Comparison of PIIINP in hypertension patients among different age groups 


\section{Comparison of BMI between hypertensive and control group.}

Table product (1) shows that there were statistically significant differences in BMI between the hypertension group and a normal improved group $(\mathrm{p}<0.05)$ to the hypertension gatherings BMI compared with the normotensive group, respectively.

Table (1): Difference between hypertensive and control group.

\begin{tabular}{|l|l|l|l|}
\hline \multirow{2}{*}{ Groups } & \multicolumn{2}{|l|}{ Mean \pm S.E. } \\
\cline { 3 - 4 } & control & $\begin{array}{l}\text { Hyperten } \\
\text { sive }\end{array}$ \\
\hline BMI & & $30.827 \pm$ & $\begin{array}{l}37.324 \quad \pm \\
1.289 *\end{array}$ \\
\hline
\end{tabular}

\section{DISCUSSION}

Comparison of PIIINP in hypertension patients compared with control groups.

Figure (1) findings showed relatively high $(p<0.05)$ in PIIINP relative to test samples in hypertensive patients.

The studies of (Agrinier et al.,2013) (Safdar et al., 2014) was agreement with the present study show increased in PIIINP in hypertension patients compared with control groups. PIIINP levels are raised In patients with PAH, PIIINP rates are higher relative to safe samples, associated with illness seriousness measures for example deteriorating WHO FC, cardiovascular record and 6MWD. Interestingly, although rates of PIIINP have been shown to increase with age elsewhere (Deng et al .,2011). We check This is possibly an immediate after-effect of a vocation in increasing income in individuals with collagen as well as with certifiable nervous recovery. Such argument is reinforced by the finding that PIIINP rates in sick people from aggravated disease were higher, furthermore, by the way that PIIINP was decidedly connected to disturbed sickness markers. Such results are consistent with those from an investigation of foundational patients with hypertension with left ventricular hypertrophy indicating raised PIIINP and TIMP1 rates announced by Agrinier et al in 2013. The (Deng et al.,2011) studies were in agreement with the results research indicate increased age in PIIINP.

\section{Comparison of BMI between hypertensive and control group}

Ghosh's (2009) study revealed a large change compared a obesity central and a fat-free mass amongst normal and samples of hypertensions, although obesity level is similar, these study reveals that hypertensive neighbourhood has suggestively increase in body central rates fat.

Obesity is likely to accelerate atherosclerosis causes extremist angina and myocardial infarction, as well as the positive correlation between fat mass distribution and CAD, the relationship of obesity in various measures (WC and bmi), the group of lipid, and the quantification of The site of the lipid (subcutaneous adipose and visceral ) in patient a with ,CHD. (Williams and Tabas, 2005; Sadeghi et al., 2013).

\section{CONCLUSION}

Conclude from the current study:

1. Procollagen type III play an important role as a diagnosis marker hypertension diagnosis.

2. PIIINP raised rates with seriousness of illness

\section{REFERENCES}

Agrinier N, ,Thilly N, ,Boivin JM, Dousset B, Alla F, Zannad F.: Prognostic value of serum PIIINP, MMP1 and TIMP1 levels in hypertensive patients: a ,community-based prospective cohort study. Fundam Clin Pharmacol 2013;27: 572-80.

Castelli WP, Anderson K:: A population at risk: Prevalence of high cholesterol levels in hypertensive patients in the Framingham study. Am J Med 1986; 80:23-32 Cisbio Bioassays company 01 - January 2017 p 1-10 Guideline, for ,a Prevention, Detection, ,Evaluation, and, Management of High Blood Pressure in Adults" (13 November 2017).

de, Simone G, Pasanisi F, .Contaldo F. Link of nonhemodynamic factors to hemodynamic ,determinants of ,left ,ventricular, hypertrophy. Hypertension 2001; 38: 13-18.

Deng W, Chen QW, Li GQ, et al. Procollagen III Nterminal peptide predicts short-term prognosis and cardiac remodeling in coronary heart disease patients with metabolic syndrome. Am J Med Sci 2011;341:10-6. 
"High Blood, Pressure ,Fact ,Sheet". CDC. 19 February 2015. Archived ,. from the original ,2016.. "How,. Is High Blood .Pressure Treated?". National Heart, Lung, and .Blood Institute. 10 September 2015. Archived from the,. original on 6 April 2016.

Hernandorena,. I; Duron, .E; Vidal, JS; Hanon, .O (July 2017). "Treatment ,.options and considerations for hypertensive patients to prevent dementia". Expert Opinion on Pharmacotherapy;(Review). 18 (10): 989 1000.

Lau, ;DH;; Nattel,; S; Kalman, JM; .Sanders, P. (August 2017).; "Modifiable, Risk Factors; and Atrial Fibrillation". Circulation(Review). 136 (6): 583-96.

Naish,; Jeannette;. Court; Denise Syndercombe.; (2014).; Medical sciences (2 ed.). p. 562.

Poulter,NR; Prabhakaran,. D; Caulfield, M; (22 August 2015). "Hypertension". Lancet. 386 (9995): 801-12.

Rogerio;. A.L. (2008). Metabolic; syndrome ;after menopause and a role of hormones. Maturitas, 60:10-18.
Sadeghi;. M.;. Pourmoghaddas;. Z.; Hekmatnia;. A.; Sanei,; H.; Tavakoli, B.; Tchernof, A. et al. (2013). Abdominal; fat distribution; and serum lipids in ;patients with and without coronary ;heart disease. Arch. Iran; Med., 16(3): $149-153$.

Safdar;.Z .MD,; .Tamez,.E ;B;A, Chan,.W ;PHD, ;Basant Arya,B MD,; Yimin Ge,; MD,; Anita. Deswal, .MD, MPH,,Bozkurt,B MD, PHD; Frost, A MD, Entman, M; MD.(2014). Circulating Collagen. Biomarkers. as Indicators of Disease. Severity in Pulmonary Arterial .Hypertension. ELSEVIER INC. Vol. 2, No. 4.

Tang;.WHW,. Kitai T, Hazen SL. Gut microbiota; in cardiovascular health .and disease. Circ ;Res.; 2017;120:1183-96.

Williams; R.R, Hunt SC, ;Hopkins P,. Stults BM, .Wu LL; Hasstedt. SJ, Barlow GK, Stephenson. SH, Lalouel J-M, Kuida H: Familial dyslipidemic hypertension: Evidence from 58 Utah families for a .syndrome present in; approximately $12 \%$ of families for a syndrome .present in approximately $12 \%$ of patients with essential hypertension. JAMA 1988;259: 3579-3586. 